\title{
Study of convective heat transfer in flat plate solar collectors
}

\author{
Yedilkhan Amirgaliyev ${ }^{1}$, Murat Kunelbayev ${ }^{1}$, Aliya Kalizhanova ${ }^{1}$, Beibut Amirgaliyev ${ }^{1}$, Ainur* ${ }^{*}$ Kozbakova $^{1}$, Omirlan \\ Auelbekov ${ }^{1}$, Nazbek Kataev ${ }^{1}$ \\ ${ }^{1}$ Institute Information and Computational Technologies CS MES RK, Kazakhstan
}

\begin{abstract}
The paper herein considers the study of convective heat transfer in flat plate solar collectors, as it is seen from the analysis on research of the heat transfer by a circular and flat tubes upon conforming the forced and free convections, placed vertically or horizontally with various liquid flow directions. There have been obtained Nusselt criterion dependencies in circular and flat pipes, which shows that corresponding equations allow defining the heat transfer intensity for all fluids with appropriate accuracy. As well there has been studied Prandtl criterion for fluids, which plays an important role in points spacing as regard to the curve. In each case the lines are with a tip $1 / 3$, as in the research herein only the laminar conditions have been considered.
\end{abstract}

Key words: flat plate solar collector, convection, convective heat transfer, solar radiatio

\section{Introduction}

To control and design many thermal systems it is necessary to specify heat transfer coefficients between a solid body and liquid [1], for instance, for solar collectors. Indeed, such thermal systems are always subject to temporal changes of some thermal parameters (solar thermal flow, liquid or solid substance temperature).

Therefore the heat transfer coefficient in the solid fluid medium cannot be considered as constant. Here is being investigated the problem of conjugated heat transfer [2]. In this case the heat transmission effect in the solid wall can't be neglected. If conjugated facts are neglected the temperature or thermal flow are under boundary conditions. However, in practice both the temperature and thermal flow on the solid body are defined simultaneously, which are linked with dynamic and energy equations [3].

It is known, that upon convective heat transfer computation according to experimental data, the effects of such heat transfer phenomena might be neglected, corresponding Nusselt numbers, as a rule, will be underestimated [4-6].

Recently, numerical methods have been applied to several researches [7-10]. Effect of bound conductiveconvective flows in channels has been studied too in $[11,12]$, with regular changes of temperature boundary conditions (temperature or thermal flow) or flow velocity. In the studies thereof it has been shown that thermal diffusion characteristic times in the solid body and fluid are the parameters dominating in the bound heat transfer. There were carried out several researches dealing with the problems of the transition process heat transfer factors in the flat plates for various boundary conditions. Rebay \& al. [13] submitted measurements of convective heat transfer local coefficients between the uniformly heated plate and air flow. Rebay \& al. [14] studied unsteady forced convective flow heat transfer along a flat plate with a sharp change of thermal flow density on the surface without constant pressure along the flow direction.

Forced convection from microstructure on the flat plate has been investigated by Rebay \& al. [15]. In [15] there has been studied the boundary layer longitudinal conductivity.

Differential method has been used to decrease differential equations with partial derivatives for ordinary differential ones, which are solved computationally by means of computer technology. Mladin \& al. [16] simulated unsteady thermal boundary layer, being developed along the plate's finite thickness upon temperature change in the lower plate surface ramp. To simulate transient heat transfer there were applied two mathematical approaches: integral method based on the methodology of Carman- Pohlhausen equations system's NavierStokes complete equation. Both methods were in the mode of stationary state, numerical methods showed that both techniques are in line for $5 \%$ at steady condition and $2,6 \%$ at transient state. In the present work there has been used purely numerical method for studying the unsteady laminar convection on the flat plate with different thickness subjected to the surface temporal change.

\section{Method of research}

* Corresponding author: ainur79@mail.ru 
In flat plate solar collectors heat absorption area and working liquid conditions are not favorable enough, particularly, when the heat receiver (boiler) is placed horizontally. Actually, the liquid motion speed is low here and it is heated from top, and, as a result, convective currents mixing the liquid do not develop. At the boiler's sloping position under known conditions there might happen the natural convection improving the heat transfer.

Task solution of heat transfer between radiant heat absorbing surface and power liquid flat heaters upon applying the forced and natural convection (first type boundary conditions) presents sufficient difficulties. In case of applying the natural convection to the forced flow the velocity gradient on the wall will depend on the interrelated parameter part, defining both forced and free flow. In that case velocity gradient $A=\left(\frac{d W_{A}}{d y}\right)_{\gamma^{i}}$ is not known in advance (for circular tube) $A=\rho \bar{W} / d$, for flat one $A=6 \bar{W} / h$, (A) can be defined from the motion equation.

Let us use the motion equation in a simplified form, omitting inertial terms, but taking into account the upward force. Supposing the liquid physical properties being constant and presenting the density in the form of linear temperature, we will obtain:

$$
\frac{\partial^{2} W_{x}}{\partial y^{2}}+\frac{g \beta\left(t_{c}-t_{0}\right)}{v}+\frac{1}{\mu} \frac{\partial P}{\partial x}=0
$$

where $\beta$ - volume coefficient; $t_{0}$ - flow temperature far from the wall, admitted as equal to the inlet temperature, as within the thermal initial section the temperature in the flow core changes ineffectually.

The equation for temperature distribution is given by:

$$
\frac{t-t_{i}}{t_{c}-t_{0}}=\frac{\int_{0}^{n} e^{-\eta^{3}} d \eta}{\int_{0}^{30} e^{-\eta^{3} d \eta}}
$$

where $t_{i}$ - wall temperature, $\eta=\left(\frac{A}{g d x}\right)_{y}^{1 / a d} y$ - new independent variable. Denominator (2) represents the gamma function, the values of which are tabulated:

$$
\int_{0}^{\infty} e^{-\eta^{3}} d \eta=\Gamma\left(\frac{3}{4}\right)=0,8930
$$

Having substituted in (1) the value from (2) and upon integrating it we can define $A=\left(\frac{d W_{x}}{d y}\right)_{y=0}$. To carry out integration we approximate (2) and reduce the equation as follows:

$$
\frac{t-t_{e}}{t_{e}-t_{0}}=1+b_{1} e^{-\eta}+b_{2} e^{-2 \eta}+b_{2} e^{-9 n}
$$

which meets boundary conditions and upon the constants appropriate selection conforms quite well with (1). Having inserted $t_{c}-t_{0}$ from (4) into (1), we find

$$
\frac{\partial^{2} W_{x}}{\partial y^{2}} \cdot \frac{g \beta\left(t_{c}-t_{0}\right)}{v}\left(1+b_{1} e^{-\eta}+b_{2} e^{-2 \eta}+b_{a} e^{-3 \eta}\right)
$$

where $D=\frac{1}{\mu} \frac{\partial P}{\partial x} \approx$ const

Boundary conditions are in the following form: $x=0, t=t_{0}$

$$
W_{x}=6 W\left(\frac{Y}{h}-\frac{Y^{2}}{h^{2}}\right) \cdot W_{x}=8 W\left(\frac{Y}{d}-\frac{Y^{2}}{d^{2}}\right)
$$

The first equation is for flat, the second - for circular tube. Having executed integration and used boundary conditions we obtain the expression for non-dimensional velocity speed on the wall. For a flat tube

$$
\begin{gathered}
\varphi=\frac{A h^{2}}{V}=6 R e+0.43 G r\left(\frac{g x}{\text { Pr } \varphi h}\right)^{1 / 8 d} \\
R e=\frac{\bar{W}_{V}}{v}: G r=\frac{g \beta\left(t_{c}-t_{0}\right) h^{a}}{V^{2}}
\end{gathered}
$$

Unfortunately, the expression thereof contains non evident $\varphi$. Therefore in (7) it was substituted with an approximate relationship:

$$
\varphi=6 R e+0.92 \frac{G r^{3 / 4}}{P r^{1 / 4}}\left(\frac{a}{h}\right)^{1 / 4 / 4}
$$

As you can see, the initial supposition about $\varphi($ or $\bar{A})$ consistency is not justified. However, $\varphi$ changes in length relatively ineffectually $\left(\varphi \sim x^{1 / 14}\right)$. Therefore, it will not be a great mistake if to use an average value in the section with the length:

$$
\bar{\varphi}=\frac{\bar{A} h^{2}}{v} 6 \operatorname{Re}+0.736 \frac{G r^{3 / 4}}{\operatorname{Pr}^{1 / 34}}\left(\frac{e}{h}\right)^{1 / 84}
$$

Let's define now local heat-transfer coefficient, assigning it to the difference between the wall temperature and liquid temperature at the inlet to the heating area. Such definition technique ( $($ ) is convenient hereby, as at small values $\frac{1}{p_{e}} \frac{x}{\mathbb{E}}$ the liquid average mass temperature changes weakly in length

$$
\alpha_{0}=\frac{g_{e}}{t_{e}-t_{0}}=-\frac{\lambda}{t_{0}-t_{0}}\left(\frac{d t}{d y}\right)_{y=0}
$$
find:

Having used the correlation obtained previously, we

$$
\left(\frac{d t}{d y}\right)_{y=0}=\left(\frac{A}{g \alpha x}\right)^{1 / 2 / 2}\left(\frac{d t}{d \eta}\right)_{\eta=0}=\left(\frac{A}{g \alpha x}\right)^{1 / 2 / a}\left(\frac{t_{c}-1}{0.89}\right)^{(11}
$$

consequently $\propto_{0}$ from (8) and (9) 


$$
\alpha_{0=} \frac{\lambda}{0.893}\left(\frac{A}{9 a x}\right)^{1 / y d}
$$

Having substituted the value $A$ from (10) in (11) we find the expression of Nusselt criterion for flow in a flat tube:

$$
N u=1.467 \sqrt[3]{\operatorname{Pe} \frac{h}{l}+0.123\left(\operatorname{GrPr} \frac{h}{l}\right)^{2 / 4}}
$$

Where $N u=\frac{\Phi d}{d} ; \quad P e=\frac{W d}{d} ; \quad G r=\frac{g \beta\left(t_{c}-t_{0}\right) d^{3}}{V^{2}}$

In case of flow in a circular tube the similar analysis brings to an expression:

$$
N u=1,615 \sqrt{\operatorname{Pe} \frac{h}{l}+0,092\left(\operatorname{GrPr} \frac{h}{l}\right)^{2 / 4}}
$$

where $\quad N U=\frac{\Phi d}{\Omega} ; \quad P e=\frac{W d}{d} ; \quad G r=\frac{g \beta\left(t_{r}-t_{0}\right] d^{3}}{V^{2}}$

Heat transfer coefficient in (11) and 12) has been assigned to the initial temperature driving force $t_{e}-t_{0}$.

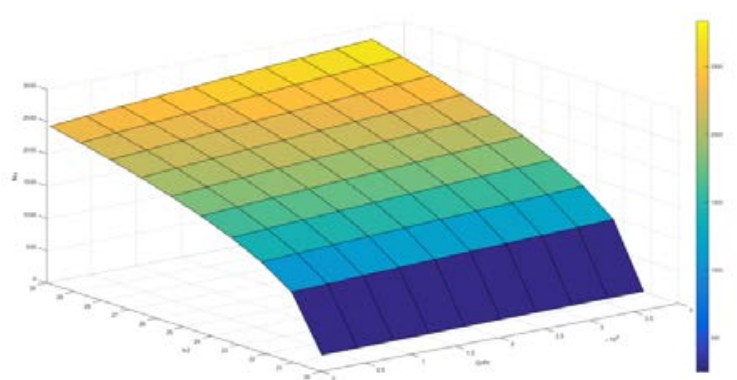

Figure 1. Nusselt criterion for liquid flow in flat tube

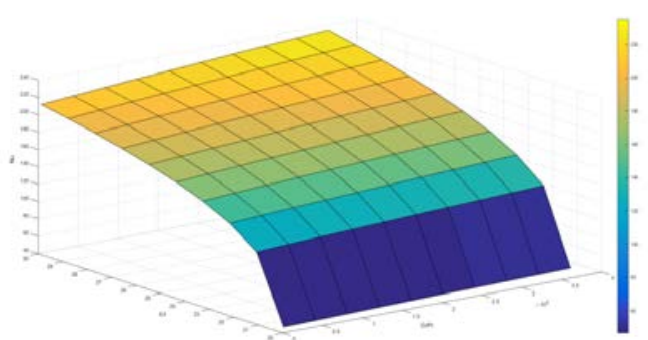

Figure 2. Nusselt criterion for liquid flow in circular tube

Upon specifying the coefficient of heat transfer from the heating area to the heated water the thermal flow is defined according to the flow rate and temperature difference of the water being heated at outlet and inlet. Water temperature is specified at outlet and inlet and the surface temperature through thermocouples readings average.

Experiments have been carried out at the heat transfer surface's obliquing angles $\phi=30^{\circ}, 35^{\circ}, 40^{\circ}$.

At that, the number $\mathrm{Re}=150-500$, i.e., the experiments have been executed mainly at water flow laminar regime.
As a determining temperature there has been accepted the water temperature and as a characteristic dimension - the channel equivalent diameter $\mathrm{d}=4 \mathrm{f} / \mathrm{S}$.

Accepted in the model dimension $\mathrm{d}$ secures its geometric similarity to experimental flat solar collectors.

In the result, experimental data in the dependency form $\mathrm{Nu}=\mathrm{f}(\mathrm{Pld} / \mathrm{l})$ and $\mathrm{Nu} / \mathrm{Pr}^{0.44}=\mathrm{f}(\mathrm{Re})$ is given in the Figures 1,2,3.

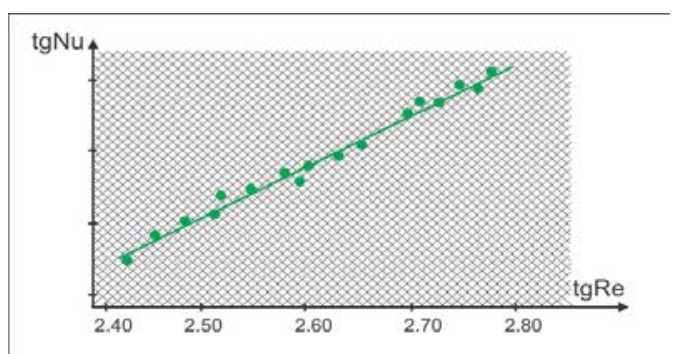

Figure 3. Nusselt criterion dependence on Reynolds criterion for liquid flow in the flat solar collector

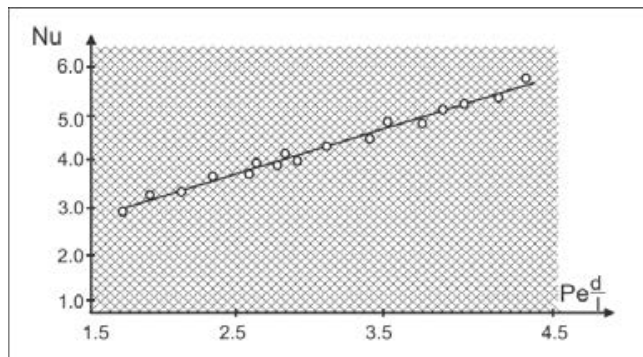

Figure 4. Nusselt criterion dependence on Reynolds criterion for liquid flow in the flat solar collector

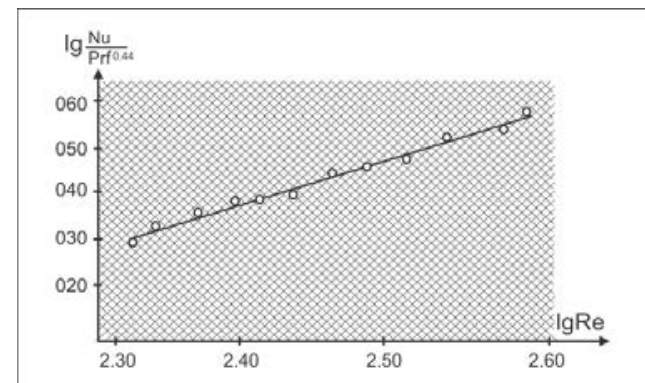

Figure 5. Dependence of Nusselt-Prandtl criterion on Reynolds criterion for the liquid flow in the flat plate solar collector

Figures 3,4,5 show, that Prandtl number for the liquid plays an important role in the points spacing as regard to the curve. In all cases the lines are with a slope $1 / 3$, as in the research herein we have considered only laminar mode.

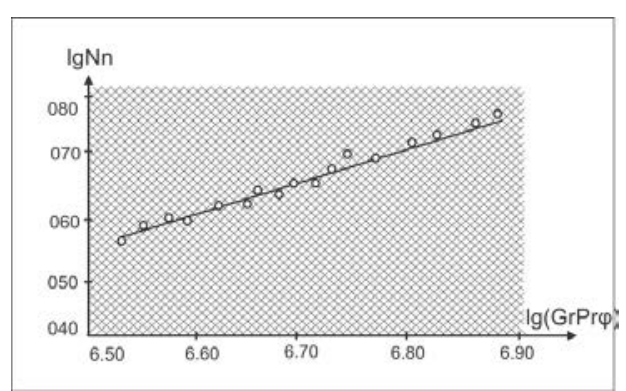

Figure 6. Nusselt criterion dependence on Grashof - Prandtl criterion for liquid flow in flat- plate solar collector 
Figure 6 demonstrates dependencies $\operatorname{lgNu}=\mathrm{f}[\lg (\mathrm{GrPr})]^{*} \quad \phi \quad$ constructed with different obliquing angles. Proceeding from the considered plotted points for heat transfer medium, we can conclude, that in all cases of sloped position the free convection in the laminar flow at values of number $\mathrm{GrPr}$ is higher than $10^{5}$. The Figure shows, that experiments outcomes are well described by the formula:

$$
\mathrm{Nu}=0,37\left(\mathrm{Pe}^{*} \mathrm{~d} / \mathrm{l}\right)^{0.35}\left(\mathrm{gr} * \operatorname{Pr}^{*} \phi\right)^{0.18}
$$

Obtained semiempirical formula allowing, in concept, processing and summarizing accumulated experimental data on the heat transfer upon convective heat transfer in the flat plate solar collectors as well gives a possibility to compare the results of theoretical investigations of heat transfer characteristics to experimental data.

Experimental data on heat transfer upon the mutual action of the forced and free convection can be broken down into three groups in compliance with the three main types of flow:

a) flow in vertical tubes bottom-up at heating and top-bottom at cooling;

б) flow in horizontal tubes at heating and cooling;

в) flow in vertical tubes top-bottom at heating and bottom-up at cooling.

In the first case the forced and free convections at the wall match in direction, in the second case they are directed mutually perpendicular, in the third - opposite.

For the cases thereof there have been obtained corresponding equations, which allow defining the heat transfer intensity for all liquids with an appropriate accuracy. Heat exchange conditions and experimental collected data of the researches thereof are given in the Table 1.

As it is seen from the above mentioned works analysis on studying the heat transfer with circular and flat tubes upon the forced and free convection conformity, ours and foreign researches have been conducted only with the tubes placed vertically or horizontally with different fluid flow directions.

Table 1

\begin{tabular}{|c|c|c|c|c|c|c|}
\hline \multirow{2}{*}{$\begin{array}{l}\text { Mutual } \\
\text { direction of } \\
\text { forced and } \\
\text { natural } \\
\text { convection }\end{array}$} & \multicolumn{3}{|c|}{ Constants } & \multicolumn{3}{|c|}{$\begin{array}{l}\text { Application } \\
\text { boundaries }\end{array}$} \\
\hline & & & & & $G r \cdot P r$ & \\
\hline 1 & 2 & 3 & 4 & 5 & 6 & 1 \\
\hline \begin{tabular}{lr}
\multicolumn{2}{l}{ Conformity: } \\
flow in vertical \\
pipes top- \\
bottom at \\
cooling and \\
bottom-up at \\
heating
\end{tabular} & 0,35 & 0,30 & 0,8 & 110 & $\begin{array}{l}8 * 10^{5}- \\
4 * 10^{8}\end{array}$ & $\begin{array}{l}20- \\
30\end{array}$ \\
\hline $\begin{array}{l}\text { Mutually } \\
\text { perpendicular } \\
\text { direction: flow } \\
\text { in horizontal } \\
\text { tubes }\end{array}$ & 0,35 & 0,60 & 0,10 & 200 & $\begin{array}{l}5 * 10^{5}- \\
1,3 * 1 \\
0^{7}\end{array}$ & $\begin{array}{l}60- \\
130\end{array}$ \\
\hline
\end{tabular}

\begin{tabular}{|c|c|c|c|}
\hline $\begin{array}{l}\text { Opposite } \\
\text { direction: flow } \\
\text { in vertical tubes } \\
\text { bottom-up at } \\
\text { cooling and } \\
\text { top-bottom at } \\
\text { heating }\end{array}$ & 300 & $\begin{array}{l}5 * 10^{5}- \\
1,33^{*} \\
10^{7}\end{array}$ & $\begin{array}{l}60- \\
130\end{array}$ \\
\hline
\end{tabular}

\section{Conclusion}

Obtained semiempiric formulae, which allow, in principle, processing and generalizing accumulated experimental data on heat transfer at convective heat transfer in flat plate solar collectors, as well they give a possibility to compare the theoretical researches outcomes of various heat transfer characteristics to experimental data.

\section{References}

1. M. Rebay, A. Arfaoui, G. Mebarki, R. Ben Maad, and J. Padet, Improvement of the Pulsed photothermal technique for the measurement of the convective heat transfer coefficient, Journal of Thermal Science, Vol. 19, pp. 357-363, (2010)

2. P. R. Kanna, and M. K. Das, Conjugate forced convection heat transfer from a flat plate by laminar plane wall jet flow, International Journal of Heat and Mass Transfer, Vol. 48, pp. 2896-2910, (2005)

3. A. Pozzi, and R. Tognaccini, Conjugated heat transfer in unsteady channel flows, International Journal of Heat and Mass Transfer, Vol. 54, pp. 4019-4027, (2011)

4. Z. G. Liu, S. Q. Liang, and M. Takei, Experimental study on forced convective heat transfer characteristics in quartz microtube, International Journal of Thermal Science, Vol. 46, 139-148, (2007)

5. Celata, M. Cumo, V. Marconi, S.J. McPhail, and G. Zummo, Microtube liquid single-phase heat transfer in laminar flow, International Journal of Heat and Mass Transfer, Vol. 49, pp. 3538-3546, (2006)

6. G. L. Morini, Viscous heating in liquid flows in micro-channels, International Journal of Heat and Mass Transfer, Vol. 48, pp. 3637-3647, (2005)

7. C. Nonino, S. Savino, S. Del Giudice, and L. Mansutti, Conjugate forced convection and heat conduction in circular microchannels, International Journal of Heat and Fluid Flow, Vol. 30, pp. 823830, (2009)

8. J. Y. Jang, and Y. W. Chiu, 3-D Transient conjugated heat transfer and fluid flow analysis for the cooling process of sintered bed, Applied Thermal Engineering, Vol. 29, pp. 2895-2903, (2009)

9. A. Barletta, E. Rossi di Schio, G. Comini, and P. D’Agaro, Conjugate forced convection heat transfer in a plane channel: Longitudinally periodic regime. 
International Journal of Thermal Science, Vol. 47, pp. 43-51, (2008)

10. A. Ates, S. Darıc1, and S. Bilir, Unsteady conjugated heat transfer in thick walled pipes involving twodimensional wall and axial fluid conduction with uniform heat flux boundary condition, International Journal of Heat and Mass Transfer, Vol. 53, pp. 5058-5064, (2010)

11. B.A. Abu-Hijleh, M. A. Al-Nimr, and M. A. Hader, Thermal equilibrium in transient conjugated forced convection channel flow, Numerical Heat Transfer A, Vol. 43, pp. 327-339, (2003)

12. L. He, and M. L. G. Oldfield, Unsteady conjugate heat transfer modeling, Journal of Turbomachinery, Vol. 133, pp. doi:10.1115-1.4001245, (2011)

13. M. Rebay, M. Lachi, and J. Padet, Measurement of the convective heat coefficients by the pulsed method-influence of the boundary layer perturbation, International Journal of Thermal Sciences, Vol. 41, pp. 1161-1175, (2002)

14. M. Rebay, and J. Padet, Parametric study of unsteady forced convection with pressure gradient, International Journal of Engineering Science, Vol. 43, pp. 655-667, (2005)

15. M. Rebay, J. Padet, and S. Kakac, Forced convection from a microstructure on a flat plate, Heat and Mass Transfer, Vol. 43, pp. 309-317, (2007)

16. E. C. Mladin, D. Stanciu, and J. Padet, Transient thermal coupling for flows over a finite thickness plate exposed to a time-dependent temperature, Proceedings of the Romanian academy, Vol. 11, pp. 163-170, (2010). 